\title{
Current surgical results with low-grade brain arteriovenous malformations
}

\author{
Matthew B. Potts, MD, ${ }^{1}$ Darryl Lau, MD, ${ }^{1}$ Adib A. Abla, MD, ${ }^{1}$ Helen Kim, PhD, ${ }^{2,3}$ \\ William L. Young, MD, ${ }^{2,3}$ and Michael T. Lawton, MD, ${ }^{1-3}$ for the UCSF Brain AVM Study Project \\ Departments of ${ }^{1}$ Neurological Surgery, ${ }^{2}$ Anesthesia and Perioperative Care, and the ${ }^{3}$ Center for Cerebrovascular Research, \\ University of California, San Francisco, California
}

\begin{abstract}
OBJECT Resection is an appealing therapy for brain arteriovenous malformations (AVMs) because of its high cure rate, low complication rate, and immediacy, and has become the first-line therapy for many AVMs. To clarify safety, efficacy, and outcomes associated with AVM resection in the aftermath of A Randomized Trial of Unruptured Brain AVMs (ARUBA), the authors reviewed their experience with low-grade AVMs-the most favorable AVMs for surgery and the ones most likely to have been selected for treatment outside of ARUBA's randomization process.
\end{abstract}

METHODS A prospective AVM registry was searched to identify patients with Spetzler-Martin Grade I and II AVMs treated using resection during a 16 -year period.

RESULTS Of the 232 surgical patients included, $120(52 \%)$ presented with hemorrhage, 33\% had Spetzler-Martin Grade I, and 67\% had Grade II AVMs. Overall, 99 patients (43\%) underwent preoperative embolization, with unruptured AVMs embolized more often than ruptured AVMs. AVM resection was accomplished in all patients and confirmed angiographically in 218 patients $(94 \%)$. There were no deaths among patients with unruptured AVMs. Good outcomes (modified Rankin Scale [mRS] score 0-1) were found in 78\% of patients, with $97 \%$ improved or unchanged from their preoperative mRS scores. Patients with unruptured AVMs had better functional outcomes $(91 \%$ good outcome vs $65 \%$ in the ruptured group, $p=0.0008$ ), while relative outcomes were equivalent $(98 \%$ improved/unchanged in patients with ruptured AVMs vs $96 \%$ in patients with unruptured AVMs).

CONCLUSIONS Surgery should be regarded as the "gold standard" therapy for the majority of low-grade AVMs, utilizing conservative embolization as a preoperative adjunct. High surgical cure rates and excellent functional outcomes in patients with both ruptured and unruptured AVMs support a dominant surgical posture for low-grade AVMS, with radiosurgery reserved for risky AVMs in deep, inaccessible, and highly eloquent locations. Despite the technological advances in endovascular and radiosurgical therapy, surgery still offers the best cure rate, lowest risk profile, and greatest protection against hemorrhage for low-grade AVMs. ARUBA results are influenced by a low randomization rate, bias toward nonsurgical therapies, a shortage of surgical expertise, a lower rate of complete AVM obliteration, a higher rate of delayed hemorrhage, and short study duration. Another randomized trial is needed to reestablish the role of surgery in unruptured AVM management.

http://thejns.org/doi/abs/10.3171/2014.12.JNS14938

KEY WORDS arteriovenous malformation; low grade; ARUBA; ruptured; unruptured; vascular disorders

$\mathrm{R}$ ESECTION is an appealing therapy for brain arteriovenous malformations (AVMs) because of its high cure rate, low complication rate, and immediacy, and has become the first-line therapy or "gold standard" for many AVMs. ${ }^{4,24}$ Surgical results have improved over time with: 1) the creation of grading systems to select patients likely to experience optimal outcomes; $;, 11,18,19,42$ 2) the development of instruments such as bipolar forceps and AVM microclips to coagulate or occlude feeding arteries effectively; 3 ) the recognition of AVM subtypes that help decipher AVM anatomy;;,9,17,34,35 and 4) the refinement of surgical approaches, strategies, and dissection techniques that facilitate safe AVM resection..$^{4,11,13,18,22,43}$ This impressive evolution of AVM surgery is at odds with the find-

ABBREVIATIONS ARUBA = A Randomized Trial of Unruptured Brain AVMs; AVM = arteriovenous malformation; $m$ RS = modified Rankin Scale; OR = odds ratio. SUBMITTED April 27, 2014. ACCEPTED December 9, 2014.

INCLUDE WHEN CITING Published online February 6, 2015; DOI: 10.3171/2014.12.JNS14938.

DISCLOSURE This research was funded in part by NIH grants R01 NS034949 (to Dr. Young) and P01 NS044155 (to the Center for Cerebrovascular Research). 
ing of "A Randomized Trial of Unruptured Brain AVMs" $(\text { ARUBA })^{23}$ that medical management alone was superior to interventional therapy for the prevention of death or stroke in patients with unruptured AVMs followed for 33 months. This finding is explained in part by the trial's $13 \%$ randomization rate, suggesting that many clinicians did not consider AVMs with low Spetzler-Martin grades (low treatment risk) to be in equipoise with medical management (high hemorrhage risk), or conversely, did not deem those with high grades (high treatment risk) to be in equipoise with medical management (low hemorrhage risk), and "selected treatment outside of the randomization process" in 177 patients, or $79 \%$ of included patients. ${ }^{23}$

Another important explanation for the ARUBA finding is the trial's surprising nonsurgical management of patients in the interventional group. ${ }^{23}$ Overall, $81 \%$ of patients were treated with embolization alone (32\%), radiosurgery alone $(33 \%)$, or combined embolization and radiosurgery $(16 \%)$, and only 17 patients $(18 \%)$ were treated surgically, with or without embolization. Therefore, the 3-fold increase in death or stroke in the interventional arm reflects current nonsurgical therapies and should not be interpreted as an indictment of AVM surgery. ${ }^{23}$ In the aftermath of ARUBA,,$^{23}$ it is important to clarify the safety, efficacy, and outcomes associated with AVM resection. Therefore, we reviewed our experience in managing Spetzler-Martin Grade I and II AVMs, the most favorable AVMs for surgery and the ones most likely to have been selected for treatment outside of ARUBA's randomization process.

\section{Methods \\ Data Collection}

This study was approved by the Institutional Review Board and conducted in compliance with Health Insurance Portability and Accountability Act regulations. The prospective registry of the University of California, San Francisco, Brain Arteriovenous Malformation Study Project was searched to identify patients with Spetzler-Martin Grade I and II AVMs who were treated with resection at our institution between 1997 and 2013. Operations were performed by the senior author (M.T.L.). The database as well as medical records, pre- and posttreatment radiological studies, and clinical follow-up evaluations were reviewed retrospectively.

\section{Outcome Evaluation}

The Spetzler-Martin grading system was used to establish AVM grade, and the Lawton-Young Supplementary grading system was used to augment surgical risk assessment. ${ }^{19,42}$ The primary outcome measure was functional outcome at last follow-up evaluation based on the modified Rankin Scale (mRS) score dichotomized to "good" (mRS score 0-1) or "poor" (mRS score 2-6). Long-term functional outcomes were only evaluated in patients with more than 30 days of follow-up. Neurological assessments were performed by a neurologist and/or a dedicated clinical research nurse, without involvement of treating neurosurgeons. The pretreatment functional status was obtained from pretreatment clinic visits or admission examinations, while follow-up information was obtained during post- treatment clinic visits, subsequent hospital admissions, or telephone interviews. The Social Security Death Index was searched for all patients with less than 30 days of follow-up to ensure that no early deaths were missed. Angiographic outcomes were determined by a neurointerventional radiologist.

\section{Statistical Analysis}

Statistical analysis was performed using the JMP program (version 11, SAS). Frequency distributions and summary statistics were calculated for all baseline characteristics and outcome measures. For all categorical variables (e.g., unruptured status), a cross-tabulation was generated and a Fisher's exact test (for $2 \times 2$ contingency tables) or Pearson chi-square test (for larger contingency tables) was used to compare distributions between groups of interest. Continuous variables were compared using an ANOVA. Statistical significance was defined as $\mathrm{p}<0.05$.

\section{Results \\ Patients and AVM Characteristics}

Between 1997 and 2013, 332 patients with SpetzlerMartin Grade I or II AVMs were managed at our institution and 234 (70\%) of these were managed surgically. Two of these patients who underwent concomitant surgical treatment for other pathologies (orbital squamous-cell carcinoma resection in 1 and extracranial-to-intracranial bypass for moyamoya disease in the other) were excluded from this cohort. Nine patients who had aneurysms clipped concomitantly were included. Baseline characteristics for the 232 surgical patients are shown in Table 1. The mean age of the study population was 38 years with a slight female predominance $(56 \%)$. The most common AVM location was the frontal lobe (34\%). Over half of the patients $(n=120)$ presented with AVM rupture and 53\% presented with an mRS score of 0 or 1 . Spetzler-Martin grades were I in $33 \%$ and II in $67 \%$. Patients presenting with AVM rupture differed from those presenting without rupture in AVM location ( $\mathrm{p}=0.0014)$, preoperative $\mathrm{mRS}$ score $(\mathrm{p}<0.0001)$, and Lawton-Young supplementary AVM grade $(\mathrm{p}<0.0001)$.

\section{Surgical Management}

Overall, 99 patients (43\%) underwent preoperative embolization, with unruptured AVMs embolized more often than ruptured AVMs (53\% vs 33\%, respectively; $\mathrm{p}=$ 0.005 ). Only 4 patients had been treated previously, 2 with stereotactic radiosurgery and 2 with both remote embolization and radiosurgery.

AVM resection was accomplished with a single stage in all but 5 patients. These 5 patients had unexpected residual AVMs noted on their postoperative angiograms and all were taken back to the operating room for complete resection. Postoperative angiograms were obtained in 218 patients (94\%, Table 2). No residual AVM was noted in 213 of these 218 patients (98\%). Repeat angiograms in the 5 patients with residual AVMs confirmed complete resection. Of the 14 patients with no postoperative angiography, 3 died during their postoperative hospitalization. The remaining 11 patients refused postoperative angiography, 
TABLE 1. Baseline characteristics of patients with low-grade AVMs

\begin{tabular}{|c|c|c|c|c|}
\hline Variable & Unruptured AVM & Ruptured AVM & $p$ Value* & Total \\
\hline Total no. of patients & 112 & 120 & & 232 \\
\hline Mean age at surgery $\pm \mathrm{SD}$ (yrs) & $39.4 \pm 15.3$ & $36.9 \pm 18.4$ & 0.16 & $38.1 \pm 17$ \\
\hline Females (\%) & $70(63)$ & $61(51)$ & 0.16 & $131(56)$ \\
\hline Presentation (\%) & & & Not tested & \\
\hline Hemorrhage & 0 & $120(100)$ & & $120(52)$ \\
\hline Seizure & $37(33)$ & 0 & & $37(16)$ \\
\hline Headache & $40(36)$ & 0 & & $40(17)$ \\
\hline Other & $35(31)$ & 0 & & $35(15)$ \\
\hline AVM location (\%) & & & 0.0014 & \\
\hline Frontal & $49(44)$ & $29(24)$ & & $78(34)$ \\
\hline Parietooccipital & $27(24)$ & $31(26)$ & & $58(25)$ \\
\hline Temporal & $22(20)$ & $22(18)$ & & $44(19)$ \\
\hline Cerebellar & $7(6)$ & $28(23)$ & & $35(15)$ \\
\hline Ventricular & $2(2)$ & $6(5)$ & & $8(3)$ \\
\hline Deep & $3(3)$ & $4(3)$ & & $7(3)$ \\
\hline Brainstem & $1(1)$ & 0 & & $1(<1)$ \\
\hline Mixed $\dagger$ & $1(1)$ & 0 & & $1(<1)$ \\
\hline AVM side (\%) & & & 0.07 & \\
\hline Rt & $59(53)$ & $57(48)$ & & $116(50)$ \\
\hline $\mathrm{Lt}$ & $52(46)$ & $55(46)$ & & $107(46)$ \\
\hline Midline & $1(1)$ & $8(7)$ & & $9(4)$ \\
\hline Preop mRS score (\%) & & & $<0.0001$ & \\
\hline 0 & $48(43)$ & $14(12)$ & & $62(27)$ \\
\hline 1 & $45(40)$ & $16(13)$ & & $61(26)$ \\
\hline 2 & $15(13)$ & $20(17)$ & & $35(15)$ \\
\hline 3 & $4(4)$ & $26(22)$ & & $30(13)$ \\
\hline 4 & 0 & $22(18)$ & & $22(9)$ \\
\hline 5 & 0 & $22(18)$ & & $22(9)$ \\
\hline Spetzler-Martin Grade (\%) & & & 0.56 & \\
\hline 1 & $37(33)$ & $39(33)$ & & $76(33)$ \\
\hline II & $75(67)$ & $81(68)$ & & $156(67)$ \\
\hline Supplementary AVM Grade (\%) & & & $<0.0001$ & \\
\hline 1 & 0 & $22(18)$ & & $22(9)$ \\
\hline 2 & $11(10)$ & $35(29)$ & & $46(20)$ \\
\hline 3 & $37(33)$ & $55(46)$ & & $92(40)$ \\
\hline 4 & $59(53)$ & $8(7)$ & & $67(29)$ \\
\hline 5 & $5(4)$ & 0 & & $5(2)$ \\
\hline Prior treatments (\%) & $61(54)$ & $42(35)$ & & $103(44)$ \\
\hline Preop embolization & $59(53)$ & $40(33)$ & 0.005 & $99(43)$ \\
\hline Remote embolization & 0 & $2(2)$ & 0.5 & $2(1)$ \\
\hline Radiosurgery & $3(3)$ & $1(1)$ & 0.1 & $4(2)$ \\
\hline
\end{tabular}

* Comparing unruptured and ruptured AVMs, an ANOVA was used for continuous variables, Fisher's exact test for $2 \times 2$ contingency tables, and Pearson chi-square test for larger contingency tables. Bold values are statistically significant.

† Refers to an AVM involving both the temporal and parietooccipital regions.

but had a mean follow-up duration of 1.6 years (range 25 days to 6.2 years).

Significant intraoperative AVM rupture occurred in 1 patient. Postoperative hemorrhages due to surgical site bleeding occurred in 3 patients, all of which required evacuation of the hematoma. Two patients were noted to have postoperative infarcts, 1 involving a lenticulostriate artery and 1 a middle cerebral artery. Finally, 2 patients had wound infections requiring surgical debridement.

Of note, an 8-year-old patient who underwent complete 
TABLE 2. Surgical results with low-grade AVMs

\begin{tabular}{lcccc}
\hline \multicolumn{1}{c}{ Variable } & Unruptured & Ruptured & p Value & Total \\
\hline Total & 112 & 120 & 232 \\
\hline Angiographic outcome (\%) & & & 0.46 & $218(94)$ \\
\hline Complete & $106(95)$ & $112(93)$ & $0(0)$ \\
\hline Residual & $0(0)$ & $0(0)$ & $14(6)$ \\
\hline No study & $6(5)$ & $8(7)$ & Not tested & $207(89)$ \\
\hline Patients w/ >30-day follow-up (\%) & $100(89)$ & $107(89)$ & Not tested & $1.7 \pm 1.8$ \\
\hline Mean duration of follow-up \pm SD (yrs) & $1.8 \pm 2.1$ & $1.6 \pm 1.4$ & Not tested & $1.2(0.1-12.8)$ \\
\hline Median duration of last follow-up in yrs (range) & $1.2(0.1-12.8)$ & $1.3(0.1-6.3)$ & 0.0008 & $161(78)$ \\
\hline Functional outcome (mRS score) & & & $31(15)$ \\
\hline $0-1$ & $91(91)$ & $70(65)$ & $8(4)$ \\
\hline 2 & $6(6)$ & $25(23)$ & $2(1)$ \\
\hline 3 & $3(3)$ & $5(5)$ & $4(2)$ \\
\hline 4 & $0(0)$ & $2(2)$ & $1(0)$ \\
\hline 5 & $0(0)$ & $4(4)$ & & $201(97)$ \\
\hline Improved/unchanged & $0(0)$ & $1(1)$ & $6(3)$ \\
\hline Worse & $96(96)$ & $105(98)$ & $2(2)$ & 0.43 \\
\hline
\end{tabular}

* Only available in 207 patients.

resection of a left temporal Grade II AVM with a negative postoperative angiogram was found to have recurrent AVM in that same location on a 5-year follow-up angiogram. He underwent a repeat resection without complication and had no residual AVM noted on either the postoperative or a repeat 5-year follow-up angiogram.

\section{Functional Outcomes}

Four patients died within 30 days of AVM resection; all of these patients had ruptured AVMs. Three patients presented with devastating AVM hemorrhages (vermian, tonsillar, and temporal AVMs), underwent uncomplicated resection, and had pre- and postoperative $\mathrm{mRS}$ scores of 5; their families withdrew care. These deaths were attributed to severity of hemorrhage rather than surgery. One patient with a deep parietal AVM had a middle cerebral artery stroke related to AVM resection and died of resulting medical complications (surgical mortality rate = $0.4 \%$ ). There were no deaths among patients with unruptured AVMs.

Long-term follow-up was available in 207 patients (89\%; Table 2). Mean duration of follow-up was 1.7 years (median 1.2 years, range 2 weeks to 12.8 years). Four additional patients had died at late follow-up, all from causes unrelated to their AVM surgery: 1 patient died of cancer 3 years postoperatively $(\mathrm{mRS}$ score $=1), 1$ patient died of renal failure 4 months postoperatively $(\mathrm{mRS}$ score $=0)$, and 2 patients died of unknown causes 1.9 years (mRS score $=1)$ and 5.7 years (mRS score $=1)$ postoperatively. The mRS score from the next-to-last clinical evaluation was used for the functional outcome analysis.

Overall, good outcomes (mRS score 0-1) were found in $78 \%$ of patients, with $97 \%$ improved or unchanged from their preoperative mRS scores (Table 2). As expected, patients with unruptured AVMs had better functional out- comes, with $91 \%$ having a good outcome at the time of the last follow-up evaluation compared with $65 \%$ in the ruptured AVM group $(p=0.0008)$. Relative outcomes were slightly better in patients with ruptured AVMs, with $98 \%$ improved or unchanged, compared with $96 \%$ in patients with unruptured AVMs.

Univariate analysis of factors associated with good (mRS score 0-1) compared with poor (mRS score $\geq 2$ ) functional outcomes identified younger age (odds ratio [OR] 0.98 for each increasing year; $p=0.03$, logistic regression), unruptured presentation (good outcomes in $88 \%$ of unruptured AVMs vs $65 \%$ of ruptured AVMs; $p=$ 0.0001, 2-tailed Fisher's exact test), and preoperative mRS scores (good outcomes in $94 \%$ and $57 \%$ with preoperative $\mathrm{mRS}$ scores of $0-1$ and $\geq 2$, respectively; $\mathrm{p}<0.0001$, chi-square test). Of note, AVM location, Spetzler-Martin and Lawton-Young supplementary grades, preoperative embolization, and time to follow-up were not significantly associated with functional outcome. The 3 variables above were fit into a logistic regression model that confirmed that young age (OR 0.98 for each increasing year; $\mathrm{p}=0.03)$ and low preoperative mRS score (OR 11.8 for mRS score $0-1$ vs $m R S$ score $\geq 2 ; p<0.0001$ ) remained significantly associated with good outcomes. The OR for hemorrhagic presentation in this model did not reach statistical significance (OR 0.97 for unruptured vs ruptured AVM; $\mathrm{p}=0.95$ ).

\section{Discussion}

\section{Surgical Results With Low-Grade AVMs}

This study exemplifies a surgical posture toward lowgrade AVMs that regards curative resection as the firstline or "gold standard" therapy for the majority of lesions, 
utilizing embolization as a preoperative adjunct and reserving radiosurgery for risky AVMs in deep, inaccessible locations, in eloquent areas that might be associated with postoperative neurological deficits, and/or with diffuse nidus morphology that might complicate microdissection. Patients were carefully selected to optimize outcomes, with a mean age of 38 years, Lawton-Young supplementary grades of 3 or less in $69 \%$ of patients, and few $(<4 \%)$ in deep locations or brainstem. Conservative embolization minimized additional treatment risk, with only $43 \%$ of patients undergoing embolization and no patients experiencing endovascular complications. Surgical cures were confirmed in all patients who underwent postoperative angiography. Overall, 6 patients (3\%) were worse neurologically after surgery, with 161 patients (78\%) in total and 91 patients (91\%) with unruptured AVMs experiencing good outcomes (mRS score 0-1). These surgical results are consistent with other reports in the literature (Table 3). ${ }^{4,11-13,24,32,37,38,40,42,43}$ In a review of 1235 patients with lowgrade AVMs, the average surgical morbidity and mortality rates were $2.2 \%$ and $0.3 \%$, respectively, with an average cure rate of $98.5 \%$ and a postoperative or delayed hemorrhage rate of $0.3 \%$ (Table 3 ).

\section{Endovascular and Radiosurgical Results With Low-Grade AVMs}

The management of AVMs in other parts of the world is diverging from the surgical approach described above. In Europe, for example, treatment is often limited only to ruptured AVMs, beginning with aggressive embolization, frequently adding radiosurgery for incompletely embolized AVMs, ${ }^{2,3,31,39}$ and rarely resorting to resection. Onyx (Covidien) is an important endovascular advancement because its high viscosity allows for slow intranidal injection, its prolonged solidification promotes deep penetration to the venous side of the AVM, and its nonadherence reduces catheter retention (J. Moret, presentation to the AANS Annual Meeting, 2014). ${ }^{31}$ Onyx has improved the efficacy of endovascular therapy with better cure rates than $N$-butyl cyanoacrylate glue, but cure rates are still low and cura- tive attempts are associated with increased complications, occlusion of critical draining veins, and adverse imaging findings in as many as $40 \%$ of patients. $1,10,15,20,25,27-30,36,41,45-47$ In a review of 1297 patients with mostly low-grade AVMs, the average endovascular morbidity and mortality rates were $6.2 \%$ and $1.6 \%$, respectively, with an average cure rate of $29 \%$ and a postoperative or delayed hemorrhage rate of $8.0 \%$ (Table 4). ${ }^{1,10,15,20,25,27-30,36,41,45-47}$ Therefore, aggressive endovascular therapy has higher procedural risks, significantly lower cure rates, and increased hemorrhage risks compared with surgery.

A similar comparison can be made with radiosurgery for low-grade AVMs. Although these lesions are ideal for radiosurgery because of their lower target volumes and higher obliteration rates, the 2- to 3-year latency period between treatment and obliteration opens a time window for AVM hemorrhage and associated complications. Radiation-induced complications are low, but in a review of 1051 patients with low-grade AVMs, $7.2 \%$ of patients hemorrhaged after treatment, resulting in morbidity and mortality rates of $6.5 \%$ and $1.2 \%$, respectively (Table 5). ${ }^{6-8,14,16,21,26,33,48}$ The $75.2 \%$ radiosurgical cure rate was substantially better than the endovascular cure rate, but still less than surgery. Therefore, despite the technological advances in endovascular and radiosurgical therapy, surgery still offers the best cure rate, lowest risk profile, and greatest protection against hemorrhage for low-grade AVMs. Surgery cannot compete with the minimally invasive appeal of these other modalities, but this issue remains secondary to functional outcome.

The results of our analysis are consistent with other systematic meta-analyses of AVM therapy not limited to low-grade AVMs. In a recent meta-analysis of 13,698 patients by van Beijnum et al. ${ }^{44}$ the complication rates and case fatality rates were $6.6 \%$ and $0.96 \%$ for embolization, $5.1 \%$ and $0.5 \%$ for radiosurgery, and $7.4 \%$ and $1.1 \%$ for surgery, respectively, with the increased surgical risks reflecting the inclusion of intermediate and high-grade AVMs. However, AVM obliteration rates were $13 \%, 38 \%$, and $96 \%$ for embolization, radiosurgery, and surgery, respectively. ${ }^{44}$ Estimates of hemorrhage risk after surgery

TABLE 3. Summary of surgical results with low-grade AVMs

\begin{tabular}{|c|c|c|c|c|c|}
\hline Authors \& Year & No. of Patients & Morbidity (\%) & Mortality (\%) & Cure Rate (\%) & Hemorrhage (\%) \\
\hline Spetzler \& Martin, 1986 & 44 & 2.3 & 0 & NA & NA \\
\hline Heros et al., 1990 & 47 & 2.2 & 2.2 & 100 & 0 \\
\hline Sundt et al., 1991 & 84 & 2.2 & 0 & 100 & 0 \\
\hline Sisti et al., 1993 & 67 & 1.5 & 0 & 94 & 0 \\
\hline Hamilton \& Spetzler, 1994 & 40 & 0.0 & 0 & 100 & NA \\
\hline Schaller \& Schramm, 1997 & 50 & 3.2 & 0 & 98 & 2 \\
\hline Schaller et al., 1998 & 81 & 0.0 & 0 & NA & NA \\
\hline Pikus et al., 1998 & 26 & 3.8 & 0 & 100 & 0 \\
\hline Hartmann et al., 2000 & 48 & 6.6 & 0 & NA & NA \\
\hline Morgan et al., 2004 & 220 & 0.9 & 0.5 & 100 & 0 \\
\hline Davidson \& Morgan, 2010 & 296 & 0.7 & 0 & 97 & NA \\
\hline Lawton, 2014 & 232 & 2.4 & 0.5 & 98 & 0 \\
\hline Total & 1235 & 2.2 (mean) & 0.3 (mean) & 98.5 (mean) & 0.3 (mean) \\
\hline
\end{tabular}


TABLE 4. Summary of endovascular results with Onyx for mostly low-grade AVMs

\begin{tabular}{lccccc}
\hline \multicolumn{1}{c}{ Authors \& Year } & No. of Patients & Morbidity (\%) & Mortality (\%) & Cure Rate (\%) & Hemorrhage (\%) \\
\hline Pérez-Higueras et al., 2005 & 45 & 15.5 & 2.0 & 22 & 8.9 \\
\hline Song et al., 2005 & 50 & 10.0 & 0.0 & 20 & 6.0 \\
\hline van Rooij et al., 2007 & 44 & 4.6 & 2.3 & 16 & 6.8 \\
\hline Weber et al., 2007 & 93 & 5.4 & 0.0 & 20 & NA \\
\hline Mounayer et al., 2007 & 94 & 4.3 & 3.2 & 28 & 8.5 \\
\hline Katsaridis et al., 2008 & 101 & 8.0 & 3.0 & 28 & 5.9 \\
\hline Pierot et al., 2009 & 50 & 8.0 & 2.0 & 8 & 8.0 \\
\hline Panagiotopoulos et al., 2009 & 82 & 7.3 & 2.4 & 20 & 12.2 \\
\hline Gao et al., 2009 & 115 & 2.6 & 0.9 & 26 & 2.6 \\
\hline Maimon et al., 2010 & 43 & 2.3 & 0.0 & 37 & 13.9 \\
\hline Xu et al., 2011 & 86 & 3.5 & 1.2 & 51 & 7.0 \\
\hline Saatci et al., 2011 & 350 & 4.3 & 1.4 & 94 & 4.0 \\
\hline Abud et al., 2011 & 17 & 5.9 & 0.0 & 24 & 8.5 \\
\hline Pierot et al., 2013 & 127 & 5.1 & 4.3 & 29.5 (mean) & 8.0 (mean) \\
\hline Total & 1297 & 6.2 (mean) & 1.6 (mean) & & \\
\hline
\end{tabular}

$\mathrm{NA}=$ not available

were $1.7 \%, 1.7 \%$, and $0.2 \%$ for embolization, radiosurgery, and surgery, respectively. ${ }^{44}$

\section{Critique of ARUBA}

How do we interpret the ARUBA findings in the context of our study? First, based on the surgical experience described above, a significant number of neurosurgical investigators in ARUBA did not consider low-grade AVMs to be in equipoise with medical management and "selected treatment outside of the randomization process" in 177 patients, or close to the number of included patients. ${ }^{23}$ Conversely, intermediate $(31.8 \%)$ and high-grade AVMs $(10.3 \%)$ that are generally considered to have a more benign natural history and are at high risk for any treatment were included in the trial, diminishing the interventional results. ${ }^{23}$

As a participating site in the ARUBA trial, we screened 473 patients, identified 87 who were eligible, and enrolled only 4 . Of the 74 ARUBA-eligible patients with sufficient follow-up for analysis, 61 were treated (including 36 with low-grade AVMs) and 13 were observed. Most treated patients underwent resection with or without preoperative embolization $(43 / 61,70.5 \%)$. Stroke and death, the primary end points by ARUBA definitions, were observed in 10 patients, including 1 in the observation group (8\%), 5 in the surgical group (11\%), and 4 in the radiosurgical group (27\%). There was no significant difference in stroke/death rates (hazard ratio 1.34, 95\% confidence interval 0.12 $14.53 ; p=0.807$ ) or clinical impairment $(p=0.68$, Fisher's exact test) between observed and treated patients. Therefore, our results in ARUBA-eligible patients were better than those reported in ARUBA, leading to an entirely different conclusion about AVM intervention. This difference was due to utilizing surgery as the primary therapy, selecting surgical patients judiciously with established outcome predictors, and developing surgical expertise through high AVM case volume.

Second, ARUBA was unusually biased toward nonsurgical therapy, with $81 \%$ of patients treated with endovascular embolization alone (32\%), radiosurgery alone (33\%),

TABLE 5. Summary of radiosurgical results with low-grade AVMs

\begin{tabular}{lccccc}
\hline \multicolumn{1}{c}{ Authors \& Year } & No. of Patients & Morbidity (\%) & Mortality (\%) & Cure Rate (\%) & Hemorrhage (\%) \\
\hline Pollock et al., 1994 & 65 & 5.0 & 3.0 & 86.0 & 7.7 \\
\hline Yamamoto et al., 1996 & 19 & NA & 0.0 & 63.2 & 2.5 \\
\hline Meder et al., 1997 & 57 & NA & NA & 65.0 & NA \\
\hline Friedman et al., 2003 & 107 & NA & NA & 66.4 & 10.4 \\
\hline Nataf et al., 2007 & 27 & NA & 0.0 & 77.8 & 10.0 \\
\hline Kano et al., 2012 & 217 & 3.2 & 2.8 & 93.0 & 6.0 \\
\hline Fokas et al., 2013 & 24 & NA & NA & 61.0 & 6.0 \\
\hline Koltz et al., 2013 & 33 & 12.1 & 0.0 & 88.0 & 9.1 \\
\hline Ding et al., 2014 & 502 & 5.6 & NA & 76.1 & 5.6 \\
\hline Total & 1051 & 6.5 (mean) & 1.2 (mean) & 75.2 (mean) & 7.2 (mean) \\
\hline
\end{tabular}

$\mathrm{NA}=$ not available 
or combined embolization and radiosurgery $(16 \%) .{ }^{23}$ The $18 \%$ of ARUBA patients treated surgically contrasts sharply with the $71 \%$ of ARUBA-eligible patients treated surgically at our site. Data on cure rates were not published with ARUBA, ${ }^{23}$ but the number of incompletely obliterated AVMs was likely significant and resulted in ongoing ruptures. Therefore, the event rates observed in KaplanMeier estimates of "as-treated" patients reflected the procedural morbidity of endovascular therapy in addition to the delayed morbidity of latent hemorrhage associated with radiosurgery. ${ }^{23}$ The outcome of such a group could never exceed that of an observational group whose only morbidity was the risk of AVM rupture.

Third, the shortage of surgical expertise in the ARUBA trial is apparent. Two-thirds of patients in the interventional group had low-grade surgical AVMs and yet only $18 \%$ underwent surgery, which is well below expectation for the gold standard therapy. ${ }^{23}$ The rates of stroke and death in this trial do not match reported surgical outcomes (Table 3). Therefore, the overall management of AVMs in ARUBA reflects a nonsurgical posture consistent with the fact that 38 of 65 total ARUBA sites were in Europe, Australia, and Brazil. ${ }^{22}$ Centers were required to manage 10 patients with AVMs per year, but there were no minimum requirements for neurosurgeons. AVM resection is among the most challenging neurosurgical procedures, and the best AVM surgeons typically perform three times ARUBA's minimum requirement annually. In a review of AVM outcome data from the National Inpatient Sample, we found that mortality rates were lowest and discharges to home were highest among neurosurgeons with the highest case volume, defined as the top decile with 30 or more AVM resections per year. Had the ARUBA trial been embraced by the neurosurgical community, the application of surgical therapy would have been higher, the interventional outcomes would have been better, and the benefits of intervention would have been obvious. Had ARUBA been more surgical with complete resections and no delayed hemorrhage in nearly all patients as described above, the event rates observed in Kaplan-Meier estimates of "as-treated" patients would have plateaued and the benefits of intervention would have been realized in much less than 10 years. Although this time interval is reasonable in a population of young patients (mean age 45 years) with long life expectancy, the trial was stopped long before reaching this crossover point (median follow-up duration of 33 months). ${ }^{23}$

\section{Another Randomized Trial: BARBADOS}

The ARUBA trial has had significant impact because it was a randomized, controlled trial. Our results with lowgrade AVMs were derived from a larger cohort of patients than ARUBA (232 vs 223) and more than twice the number of treated patients (232 vs 98), but the impact of our results is limited by study design. Although the University of California, San Francisco AVM database is prospectively maintained by statisticians with input from multiple disciplines, including functional outcomes from dedicated clinical research nurses and neurologists (not treating neurosurgeons), and angiographic outcomes from neurointerventional radiologists, this case series is influenced by referral biases, institutional biases, and selection biases.
Patients are selected according to established outcome predictors embodied in the Spetzler-Martin and LawtonYoung Supplementary grading systems. Furthermore, our site is a high-volume center with dedicated experts who have collaborated as a team for decades, which might set a high surgical benchmark but lower the generalizability of our results. As important as these surgical results are in ARUBA's aftermath, another trial is needed to reestablish the role of surgery in AVM management, this time conducted and embraced by the neurosurgical community.

We propose BARBADOS: Beyond ARUBA-Randomized low-grade Brain AVM stuDy: Observation versus Surgery. The elements of the trial are obvious from the name, and efforts are ongoing to organize, fund, and initiate it. There is now urgency among neurosurgeons to respond to ARUBA, which we expect to increase the acceptance of such a trial. In the meantime, the management of ruptured AVMs should remain unaffected by ARUBA and surgery should remain a dominant therapy because of its ability to evacuate hematomas, relieve intracranial pressure, and work through hematoma cavities.

\section{Conclusions}

Surgery should be regarded as the first-line or gold standard therapy for the majority of low-grade AVMs, utilizing conservative embolization as a preoperative adjunct. High surgical cure rates and excellent functional outcomes in both ruptured and unruptured patients support a dominant surgical posture, with radiosurgery reserved for risky AVMs in deep, inaccessible, and highly eloquent locations. In the aftermath of ARUBA, additional randomized trials are needed to validate the role of resection.

\section{References}

1. Abud DG, Riva R, Nakiri GS, Padovani F, Khawaldeh M, Mounayer C: Treatment of brain arteriovenous malformations by double arterial catheterization with simultaneous injection of Onyx: retrospective series of 17 patients. AJNR Am J Neuroradiol 32:152-158, 2011

2. Blackburn SL, Ashley WW Jr, Rich KM, Simpson JR, Drzymala RE, Ray WZ, et al: Combined endovascular embolization and stereotactic radiosurgery in the treatment of large arteriovenous malformations. J Neurosurg 114:1758-1767, 2011

3. Dalyai R, Theofanis T, Starke RM, Chalouhi N, Ghobrial G, Jabbour P, et al: Stereotactic radiosurgery with neoadjuvant embolization of larger arteriovenous malformations: an institutional experience. Biomed Res Int 2014:306518, 2014

4. Davidson AS, Morgan MK: How safe is arteriovenous malformation surgery? A prospective, observational study of surgery as first-line treatment for brain arteriovenous malformations. Neurosurgery 66:498-505, 2010

5. Davies JM, Kim H, Young WL, Lawton MT: Classification schemes for arteriovenous malformations. Neurosurg Clin $\mathbf{N}$ Am 23:43-53, 2012

6. Ding D, Yen CP, Xu Z, Starke RM, Sheehan JP: Radiosurgery for low-grade intracranial arteriovenous malformations. J Neurosurg 121:457-467, 2014

7. Fokas E, Henzel M, Wittig A, Grund S, Engenhart-Cabillic $\mathrm{R}$ : Stereotactic radiosurgery of cerebral arteriovenous malformations: long-term follow-up in 164 patients of a single institution. J Neurol 260:2156-2162, 2013 
8. Friedman WA, Bova FJ, Bollampally S, Bradshaw P: Analysis of factors predictive of success or complications in arteriovenous malformation radiosurgery. Neurosurgery 52:296-308, 2003

9. Gabarrós Canals A, Rodríguez-Hernández A, Young WL, Lawton MT: Temporal lobe arteriovenous malformations: anatomical subtypes, surgical strategy, and outcomes. J Neurosurg 119:616-628, 2013

10. Gao K, Yang XJ, Mu SQ, Li YX, Zhang YP, Lü M, et al: Embolization of brain arteriovenous malformations with ethylene vinyl alcohol copolymer: technical aspects. Chin Med J (Engl) 122:1851-1856, 2009

11. Hamilton MG, Spetzler RF: The prospective application of a grading system for arteriovenous malformations. Neurosurgery 34:2-7, 1994

12. Hartmann A, Stapf C, Hofmeister C, Mohr JP, Sciacca RR, Stein BM, et al: Determinants of neurological outcome after surgery for brain arteriovenous malformation. Stroke 31:2361-2364, 2000

13. Heros RC, Korosue K, Diebold PM: Surgical excision of cerebral arteriovenous malformations: late results. Neurosurgery 26:570-578, 1990

14. Kano H, Lunsford LD, Flickinger JC, Yang HC, Flannery TJ, Awan NR, et al: Stereotactic radiosurgery for arteriovenous malformations, Part 1: management of Spetzler-Martin Grade I and II arteriovenous malformations. J Neurosurg 116:11-20, 2012

15. Katsaridis V, Papagiannaki C, Aimar E: Curative embolization of cerebral arteriovenous malformations (AVMs) with Onyx in 101 patients. Neuroradiology 50:589-597, 2008

16. Koltz MT, Polifka AJ, Saltos A, Slawson RG, Kwok Y, Aldrich EF, et al: Long-term outcome of Gamma Knife stereotactic radiosurgery for arteriovenous malformations graded by the Spetzler-Martin classification. J Neurosurg 118:74-83, 2013

17. Lawton MT: Seven AVMs: Tenets and Techniques for Resection. New York: Thieme, 2014

18. Lawton MT: Spetzler-Martin Grade III arteriovenous malformations: surgical results and a modification of the grading scale. Neurosurgery 52:740-749, 2003

19. Lawton MT, Kim H, McCulloch CE, Mikhak B, Young WL: A supplementary grading scale for selecting patients with brain arteriovenous malformations for surgery. Neurosurgery 66:702-713, 2010

20. Maimon S, Strauss I, Frolov V, Margalit N, Ram Z: Brain arteriovenous malformation treatment using a combination of Onyx and a new detachable tip microcatheter, SONIC: shortterm results. AJNR Am J Neuroradiol 31:947-954, 2010

21. Meder JF, Oppenheim C, Blustajn J, Nataf F, Merienne L, Lefkoupolos D, et al: Cerebral arteriovenous malformations: the value of radiologic parameters in predicting response to radiosurgery. AJNR Am J Neuroradiol 18:1473-1483, 1997

22. Mohr JP, Moskowitz AJ, Stapf C, Hartmann A, Lord K, Marshall SM, et al: The ARUBA trial: current status, future hopes. Stroke 41:e537-e540, 2010

23. Mohr JP, Parides MK, Stapf C, Moquete E, Moy CS, Overbey JR, et al: Medical management with or without interventional therapy for unruptured brain arteriovenous malformations (ARUBA): a multicentre, non-blinded, randomised trial. Lancet 383:614-621, 2014

24. Morgan MK, Rochford AM, Tsahtsarlis A, Little N, Faulder KC: Surgical risks associated with the management of Grade I and II brain arteriovenous malformations. Neurosurgery $\mathbf{5 4 : 8 3 2 - 8 3 9 , 2 0 0 4}$

25. Mounayer C, Hammami N, Piotin M, Spelle L, Benndorf G, Kessler I, et al: Nidal embolization of brain arteriovenous malformations using Onyx in 94 patients. AJNR Am J Neuroradiol 28:518-523, 2007

26. Nataf F, Schlienger M, Bayram M, Ghossoub M, George B,
Roux FX: Microsurgery or radiosurgery for cerebral arteriovenous malformations? A study of two paired series. Neurosurgery 61:39-50, 2007

27. Panagiotopoulos V, Gizewski E, Asgari S, Regel J, Forsting M, Wanke I: Embolization of intracranial arteriovenous malformations with ethylene-vinyl alcohol copolymer (Onyx).

AJNR Am J Neuroradiol 30:99-106, 2009

28. Pérez-Higueras A, López RR, Tapia DQ: Endovascular treatment of cerebral AVM: our experience with onyx. Interv Neuroradiol 11 (Suppl 1):141-157, 2005

29. Pierot L, Cognard C, Herbreteau D, Fransen H, van Rooij WJ, Boccardi E, et al: Endovascular treatment of brain arteriovenous malformations using a liquid embolic agent: results of a prospective, multicentre study (BRAVO). Eur Radiol 23:2838-2845, 2013

30. Pierot L, Januel AC, Herbreteau D, Barreau X, Drouineau J, Berge J, et al: Endovascular treatment of brain arteriovenous malformations using onyx: results of a prospective, multicenter study. J Neuroradiol 36:147-152, 2009

31. Pierot L, Kadziolka K, Litré F, Rousseaux P: Combined treatment of brain AVMs with use of Onyx embolization followed by radiosurgery. AJNR Am J Neuroradiol 34:1395-1400, 2013

32. Pikus HJ, Beach ML, Harbaugh RE: Microsurgical treatment of arteriovenous malformations: analysis and comparison with stereotactic radiosurgery. J Neurosurg 88:641-646, 1998

33. Pollock BE, Lunsford LD, Kondziolka D, Maitz A, Flickinger JC: Patient outcomes after stereotactic radiosurgery for "operable" arteriovenous malformations. Neurosurgery 35:1-8, 1994

34. Potts MB, Young WL, Lawton MT: Deep arteriovenous malformations in the basal ganglia, thalamus, and insula: microsurgical management, techniques, and results. Neurosurgery 73:417-429, 2013

35. Rodríguez-Hernández A, Kim H, Pourmohamad T, Young WL, Lawton MT: Cerebellar arteriovenous malformations: anatomic subtypes, surgical results, and increased predictive accuracy of the supplementary grading system. Neurosurgery 71:1111-1124, 2012

36. Saatci I, Geyik S, Yavuz K, Cekirge HS: Endovascular treatment of brain arteriovenous malformations with prolonged intranidal Onyx injection technique: long-term results in 350 consecutive patients with completed endovascular treatment course. J Neurosurg 115:78-88, 2011

37. Schaller C, Schramm J: Microsurgical results for small arteriovenous malformations accessible for radiosurgical or embolization treatment. Neurosurgery 40:664-674, 1997

38. Schaller C, Schramm J, Haun D: Significance of factors contributing to surgical complications and to late outcome after elective surgery of cerebral arteriovenous malformations. J Neurol Neurosurg Psychiatry 65:547-554, 1998

39. Schwyzer L, Yen CP, Evans A, Zavoian S, Steiner L: Longterm results of gamma knife surgery for partially embolized arteriovenous malformations. Neurosurgery 71:1139-1148, 2012

40. Sisti MB, Kader A, Stein BM: Microsurgery for 67 intracranial arteriovenous malformations less than $3 \mathrm{~cm}$ in diameter. J Neurosurg 79:653-660, 1993

41. Song D, Leng B, Gu Y, Zhu W, Xu B, Chen X, et al: Clinical analysis of 50 cases of BAVM embolization with Onyx, a novel liquid embolic agent. Interv Neuroradiol 11 (Suppl 1): $179-184,2005$

42. Spetzler RF, Martin NA: A proposed grading system for arteriovenous malformations. J Neurosurg 65:476-483, 1986

43. Sundt TM Jr, Piepgras DG, Stevens LN: Surgery for supratentorial arteriovenous malformations. Clin Neurosurg 37:49-115, 1991

44. van Beijnum J, van der Worp HB, Buis DR, Al-Shahi Salman 
R, Kappelle LJ, Rinkel GJ, et al: Treatment of brain arteriovenous malformations: a systematic review and meta-analysis. JAMA 306:2011-2019, 2011

45. van Rooij WJ, Sluzewski M, Beute GN: Brain AVM embolization with Onyx. AJNR Am J Neuroradiol 28:172-178, 2007

46. Weber W, Kis B, Siekmann R, Kuehne D: Endovascular treatment of intracranial arteriovenous malformations with onyx: technical aspects. AJNR Am J Neuroradiol 28:371377, 2007

47. Xu F, Ni W, Liao Y, Gu Y, Xu B, Leng B, et al: Onyx embolization for the treatment of brain arteriovenous malformations. Acta Neurochir (Wien) 153:869-878, 2011

48. Yamamoto M, Jimbo M, Hara M, Saito I, Mori K: Gamma knife radiosurgery for arteriovenous malformations: longterm follow-up results focusing on complications occurring more than 5 years after irradiation. Neurosurgery 38:906914, 1996

\section{Author Contributions}

Conception and design: Lawton, Potts, Young. Acquisition of data: all authors. Analysis and interpretation of data: all authors. Drafting the article: Lawton, Potts, Kim. Critically revising the article: Lawton, Potts, Kim. Reviewed submitted version of manuscript: Lawton, Potts, Lau, Kim. Approved the final version of the manuscript on behalf of all authors: Lawton. Statistical analysis: Lawton, Potts, Lau, Abla, Kim. Administrative/technical/material support: all authors. Study supervision: Lawton, Potts, Kim, Young.

\section{Correspondence}

Michael T. Lawton, Department of Neurological Surgery, University of California, San Francisco, 505 Parnassus Ave., M780, Box 0112, San Francisco, CA 94143-0112. email: michael.lawton@ucsf.edu. 